Original Research Paper

\title{
An Algorithm To Determine The Maturity Improvement Plan For Information System Risk Management. Application On A Case Study
}

\author{
${ }^{1}$ Soumaya Amraoui, ${ }^{1,2,3}$ Mina EImaallam and ${ }^{3}$ Hicham Bensaid \\ ${ }^{1}$ IMS Team, ADMIR Laboratory, Rabat IT Center, ENSIAS, Mohammed V University, Rabat, Morocco \\ ${ }^{2}$ LYRICA Laboratory, School of Information Sciences, Rabat, Morocco \\ ${ }^{3}$ Smart, Embedded, Enterprise and Distributed Systems (SEEDS) CEDOC-2TI, INPT, Rabat, Morocco
}

\section{Article history:}

Received: 27-03-2019

Revised: 20-05-2019

Accepted: 31-07-2019

Corresponding Author:

Soumaya Amraoui

IMS Team, ADMIR

Laboratory, Rabat IT center,

ENSIAS, Mohammed V

University, Rabat, Morocco

Email: soumaya.amraoui@gmail.com

\begin{abstract}
A good and relevant Risk Management process is a key issue when Information System effective governance is concerned. Therefore, several paradigms have been devised to help achieving such goal. Among these paradigms, maturity models are quite popular. The main aim of a maturity model is to help users improve their activities capability. However, one of the major challenges encountered when using these models is the definition of the improvement plan after the evaluation. This challenge is all the stronger and costly when it comes to an activity whose elements or phases have an important interdependence such as IS risk management. In this article, we propose an algorithm called "Path Prerequisites" to help users define a graduate improvement plan, easily and efficiently, from a given maturity level to a target one, while handling criteria dependencies constraints. The algorithm is based on an acyclic graph representation of the control objectives and the dependencies among them and it corresponds to a guided (backwards) traversal of the graph. We assess the algorithm by applying it to a study case.
\end{abstract}

Keywords: Information System, Maturity, Maturity Model, Focus Area Model, Risk Management

\section{Introduction}

The governance of an information system is the definition and the implementation of the strategy and the necessary tools for the achievement of its objectives. However, these objectives can be achieved only if the information system is protected against any potential threats through the implementation of an effective Risk Management (RM) process. Hence the need of a maturity model for information system risk management process.

A Maturity Model is a technique that has been proved to be valuable in measuring different aspects of a process or an organization (Proenca and Borbinha, 2016). It identifies deficiencies in process structure and management and unsatisfactory performance causes (Mayer and Fagundes, 2009). Maturity models are available to respond to many different challenges (Carvalho et al., 2019). They provide information for organizations to address the problems and challenges in a structured way, providing both a reference point to assess the capabilities and a road map for improvement (Caralli and Knight, 2012b). Based on the assumption of predictable patterns of organizational evolution and change, maturity models typically represent theories about how an organization's capabilities evolve in a stage-by-stage manner along an anticipated, desired, or logical path. They give guidance through an evolutionary process by incorporating formality into the promizing improvement activities (Mettler, 2010). These tools allow self-assessment and provide a relevant benchmark of these activities in relation to best practices (Elmaallam and Kriouile, 2013). During the last five decades, several maturity models have been proposed, which differ not only in terms of the number of stages, but also on maturity-influencing factors and intervention fields (Rocha, 2011). However, to be effective a maturity model should be relevant and should deal with the real issue of the targeted assessment. The first question that organizations and researchers try to answer is then: which maturity model best meets the requirements of the assessed activity? The second and more important question is: what efficient method to use for defining the improvement plan after assessing an activity? This question is more important when there is 
interdependency between the assessed activity elements which involves significant effort to elaborate improvement plan. To the best of our knowledge, no existing work adequately addresses this last issue. They rather only treat the assessment aspect. In this article we focus on the Focus Area (FA) model and propose an algorithm ("Path Prerequisites") to assist its users to define an improvement plan once the evaluation of the maturity is made. The remainder of this paper is structured as follows: Section two presents the research methodology. Section three gives the research background as a prerequisite for the "design and development" phase. Section three introduces the "Path Prerequisites" algorithm. Section four illustrates the "demonstration and evaluation" phases which are an application of the "Path Prerequisites" algorithm to the model "ISR3M" (Elmaallam et al., 2019), a maturity model for assessing the information system risk management. Section five concludes.

\section{Research Methodology}

We start by introducing the Design Science Process that we use for presenting our research approach (Peffers et al., 2007). The Design Science Research (DSR) methodology (Hevner et al., 2004) focuses on the development of a new artefact. It is particularly suitable for research on the process assessment discipline (Carlsson et al., 2011). In order to develop our artefact, we follow the six phases of the DSR approach:

1. Phase 1: Problem identification and motivation The problem motivating our work is how to develop an approach for defining maturity improvement plan while optimizing efforts for information system risk management

2. Phase 2: Define the objectives for a solution
The objective of our solution is to devise an algorithm, called "Path Prerequisites", to define an improvement plan for IS risk management maturity model

3. Phase 3: Design and development

The "Path Prerequisites" algorithm Focus Area maturity model development method is based on the Focus Area maturity matrix, as described in background section and graph analysis method to compute all possible paths from a target configuration to an initial configuration while optimizing the effort

4. Phase 4 and 5: Demonstration and Evaluation For these two phases, an application of the algorithm is presented in the fifth and sixth sections. It concerns the definition of improvement plan of information system risk management maturity model

5. Phase 6: Communication

This phase is assured by publication of the algorithm in scientific conferences and journals and its intended use by professionals, especially in information system risk management maturity improvement

\section{Background}

\section{Information System as a Work System}

Several definitions of an Information System (IS) exist in the literature (Carvalho et al., 2019). In our work, we adopt that of the IS as a Work System (WS) (Alter and Sherer, 2004). We opt for this definition since it clearly identifies the components of an IS and thus provide more relevant results of IS risk management activities. A Work System is a system (as depicted on Fig. 1) in which human participants and/or machines perform work (processes and activities) using the information, technology and other resources to produce specific products and/or services for of internal or external customers (Alter and Sherer, 2004).

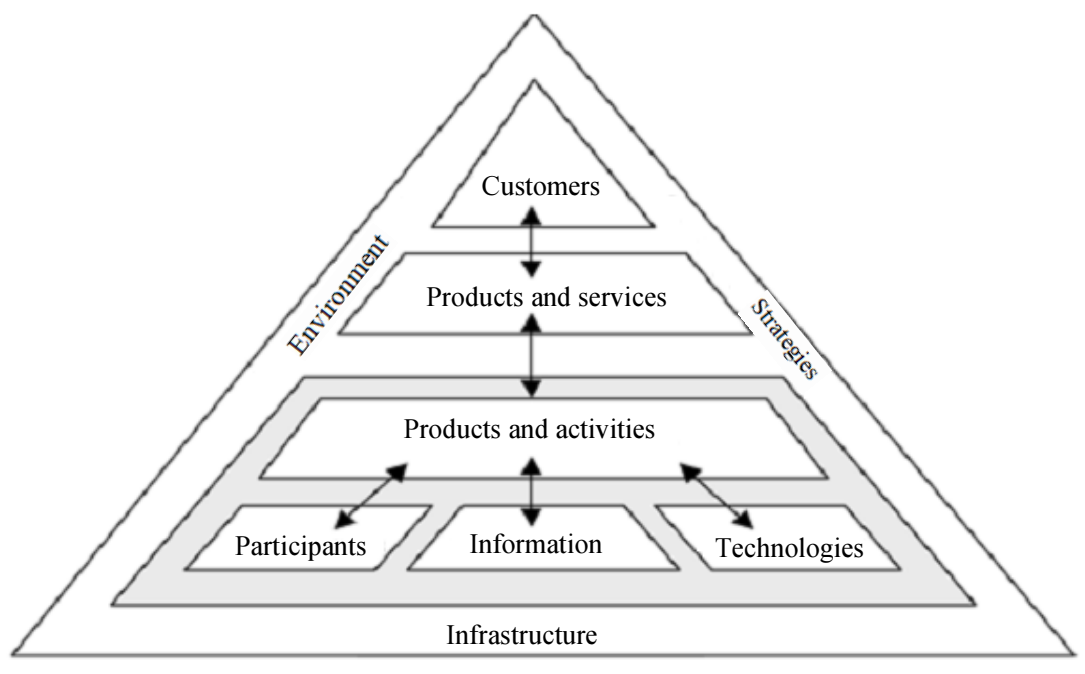

Fig. 1: The work system framework (Alter and Sherer, 2004) 
An information system is a work system whose processes and activities are devoted to processing information, that is, capturing, transmitting, storing, retrieving, manipulating and displaying information (Alter and Sherer, 2004).

\section{IS Risk Management}

Risk management can be defined as "the set of coordinated activities for the purpose of leading and controlling an organization toward risk" (ISO, 2009b). Moreover, IS risk management is an ongoing business of identifying and mitigating risks (Alter and Sherer, 2004). IS risk management activities must be included in a realistic model that describes efficiently the overall system of the organization, because the recognition of risk factors encourages appropriate risk reduction tactics (Alter and Sherer, 2004). For example, project managers who don't have an essential skill can use an employee or consultant having such ability or completely modify the project skills (Alter and Sherer, 2004) otherwise. The risk reduction tactics available depend on the objectives and expectations that apply (Alter and Sherer, 2004). For example, a project that aims to minimize costs finds additional difficulty in hiring expensive consultants (Alter and Sherer, 2004). Radut (2009) considers that IS risk management is "a framework for classifying, assessing and mitigating IS risks until achieving an acceptable threshold". Olzak (2008) argues that information risk management is "the proper employment of tools and methods leading to security controls implementation allowing a business risk extenuation and by then insuring information performance. This must be done in a way that maintains for each personnel and processes, protected by these controls and using the systems, to the highest level of prospective operational efficiency." When developing its IS security risk model, Mayer and Fagundes (2009) adopts the definition of ISO (2009a), which considers that IS risk management is "the set of coordinated activities to guide and control an organization in relation to the IS risks to which it is exposed". According to Valentin and Vasile (2008), IT risk management consists of analyzing the risk knowledge taken by the company through its IT systems in terms of business impact. Salvati (2008) believes that beyond the procedural aspects that are often emphasized in the description of IS risk management activities, it is necessary to highlight the decision-making aspects as well. In such an interpretation, IS risk management represents a structured approach to risk-informed decision-making which aligns the functioning of the enterprise information system to its risk appetite (Salvati, 2008). In the same vein, the Risk Management Guide for US Department of Commerce Information Technology Systems argues that information risk management must exist not only to protect its IT assets but also to "protect organization and its ability to fulfill its mission", (Woodall et al., 2014). Therefore, the risk management process should not be primarily treated as a technical function performed by IT experts who operate and manage the computer system, but as a core management function of the organization (Stoneburner et al., 2002). Information risk management needs to be incorporated into all decisions and everyday operations, can afterwards provided to be used effectively, regarded as tool to manage information proactively rather than reactively. Managing the risks of an information system involves managing the risks of its nine axes in relation to their evaluation elements. According to Elmaallam and Kriouile (2015), the evaluation elements of each axis are identified through (1) the missions and requirements of the work system framework as defined in the literature (Alter and Sherer, 2004), (2) the application of the theory Resource Based-View (RBV) (Wade and Hulland, 2004) on IS defined as WS considering both dynamic resources such as skills, as static as the technical infrastructure, (3) the IS risk factors (Alter and Sherer, 2004) and (4) interviews with IS experts. Table 1 lists the evaluation elements for each component.

\section{Maturity Model Architectures}

Maturity models typically include a sequence of levels (or stages) that form an anticipated, desired and logical path from an initial state to maturity (Röglinger et al., 2012). An organization's current maturity level represents its capabilities regarding specific class of objects and application domain (Rosemann and de Bruin, 2005). Maturity models are used to assess as-is situations, to guide improvement initiatives and to control progress (Iversen et al., 1999). After defining the maturity level of an activity or process, users have to define an improvement plan. The latter corresponds to the set of actions that must be achieved to reach a desired level maturity of the assessed activity. There are three types of maturity model architectures (Van Steenbergen et al., 2007). The first two architectures are qualified as "Fixed Level Architectures". These are "staged" and "continuous" architectures. The staged architecture is characterized by several Maturity Levels (ML). Every level groups a set of maturity domains. A level is reached if all requirements of its domains are verified. Table 2 illustrates the staged architecture which has $n$ levels. Domain $k$ having the level $n$ means that all requirements of this domain for this level are verified. The organization can have different levels for different domains.

The continuous architecture measures the domain's capacity. It defines a scale of skill levels for the latter. A domain reaches a level of aptitude if it satisfies all the corresponding requirements. 
Table 3 illustrates the continuous architecture. An organization having the level $j$ means that all corresponding domains verify the requirement of this level. In the same example, the activity has level 2 . The most recognized model in this architecture is Capability Maturity Model Integration (CMMI). The later addresses three areas of interest: Product and service development, Service establishment and management and finally Product and service acquisition. It has level 5 for the both staged and continuous architectures. The CMMI-Like models are the models which use the CMMI architecture but for other disciplines. They are widely used but present certain limits. The most important limit, in the present research context, is the strong focus on formalization of improvement activities accompanied by extensive bureaucracy (Herbsleb and Goldenson, 1996), in absence of formal method which can help in fast, not expensive and reliable decision-making. The third type is the test process improvement model proposed by (Koomen and Baarda, 2006). This is the "Focus Area model" (FA). It is based on the idea that each area of maturity has its own evolution. It is interesting for assessing activity with interdependencies between their various domains. For this reason, the FA is the most adequate model for risk management process and is then developed in section 3.4.

Table 4 illustrates this architecture. The organization has level 2. But each domain has its own level. Domain 1 has level $m$. domain 2 has level 2 . Etc. The FA model is detailed in section 3.4.

Table 1: Focus Area architecture

\begin{tabular}{ll}
\hline Axis & Evaluation element \\
\hline IT & Complexity \\
& Modifiability \\
& Competitive importance \\
& Potential of credibility \\
& Strategic profile \\
Participants & Competence \\
& Cooperation \\
Information & Stability \\
& Security \\
Process & Reliability \\
& Relevance \\
& Agility \\
& Formalization \\
& Updating \\
Product & Interaction \\
& Coherence \\
Customer & Compliance with requirements \\
& Quality \\
& Exploitation \\
Infrastructure & Needs \\
& Satisfaction \\
Strategy & Competence \\
Environment & Cooperation \\
& Technical infrastructure \\
\hline & Human infrastructure \\
& Informational infrastructure \\
& Alignment \\
& Contribution \\
& Culture \\
Intra Enterprise regulations \\
\hline
\end{tabular}

Table 2: Fixed level $(n)$ staged architecture

\begin{tabular}{lllll}
\hline & Level 1 & Level 2 & $\ldots$ & Level $n$ \\
\hline Domain 1 & $\mathrm{X}$ & & & \\
Domain 2 & $\mathrm{X}$ & & & \\
Domain 3 & & $\mathrm{X}$ & & \\
$\ldots$ & & & \\
Domain $k$ & & & $\mathrm{X}$ \\
\hline
\end{tabular}

Table 3: Fixed Level $(j)$ continuous architecture

\begin{tabular}{lllll}
\hline & Level 1 & Level 2 & $\ldots$ & Level $j$ \\
\hline Domain 1 & $\mathrm{X}$ & $\mathrm{X}$ & $\mathrm{X}$ & $\mathrm{X}$ \\
Domain 2 & $\mathrm{X}$ & $\mathrm{X}$ & & $\mathrm{X}$ \\
Domain 3 & $\mathrm{X}$ & $\mathrm{X}$ & $\mathrm{X}$ & \\
$\ldots$ & $\mathrm{X}$ & $\mathrm{X}$ & $\mathrm{X}$ & \\
Domain $k$ & $\mathrm{X}$ & $\mathrm{X}$ & $\mathrm{X}$ & $\mathrm{X}$ \\
\hline
\end{tabular}

Table 4: Focus area architecture

\begin{tabular}{llllll}
\hline & Level 1 & Level 2 & $\ldots$ & Level $m$ & $\ldots$ \\
\hline Domain 1 & $\mathrm{X}$ & $\mathrm{X}$ & $\mathrm{X}$ & $\mathrm{X}$ & \\
Domain 2 & & $\mathrm{X}$ & & & \\
Domain 3 & & $\mathrm{X}$ & & $\mathrm{X}$ & $\mathrm{X}$ \\
$\ldots$ & $\mathrm{X}$ & $\mathrm{X}$ & $\mathrm{X}$ & & \\
Domain $k$ & & $\mathrm{X}$ & $\mathrm{X}$ & & $\mathrm{X}$ \\
\hline
\end{tabular}

\section{Focus Area Model}

"Focus Area (FA)" (Steenbergen et al., 2010) is a maturity model design approach developed using the Design Science Research (DSR) process (Peffers et al., 2007). FA Maturity models aim to support the continuous and progressive improvement of software testing (Koomen and Baarda, 2006). A Focus Area is a well-defined coherent subset of a Functional Domain (Steenbergen et al., 2010). The total set of focus areas is a partition of the functional domain, i.e. different focus areas are disjointed and the union of all these focus areas is the complete functional domain (Steenbergen et al., 2010). In this category of models each focus area has its own number of specific maturity levels. The overall maturity of an organization is expressed as a combination of the maturity levels of these focus areas. The approach proposed by (Steenbergen et al., 2010) consists of four steps: (1) Scoping: Identify and scope domain, (2) design model: Determine focus area, capabilities, dependencies and position capabilities in matrix, (3) Instrument development: Develop assessment instrument and define improvement actions, (4) implementation and exploitation: Implement maturity model, improve matrix iteratively and communicate results.

The proposed approach illustrated in Fig. 2 is modeled using the notation presented by (Weerd and Brinkkemper, 2008), which is based on standard UML conventions, with some minor adjustments. The maturity matrix is the key deliverable of the design phase. It includes FA capabilities (or Control Objectives (CO): A, $\mathrm{B}, \mathrm{C}$, etc.) which give a score for each activity domain or 
Focus Area. Those capabilities are based on their order and dependencies. It provides the maturity level once the instrument has been designed and also defines improvement paths. An organization reaches overall maturity level ' $l$ ' $(0 \leq l \leq \max$ levels defined in matrices) if:

- All capacities located in the column corresponding to the level ' $l$ ' are verified

- All capacities located in the left of the column corresponding to the level ' $l$ ' are verified

- There is at least one capacity on the right of the column corresponding to the level ' $l$ ' that is unverified

Figure 3 gives an example of an FA maturity matrix. This later contains 18 domains and 13 levels.
The first "Development of Architecture (DA)" has three control objectives: DA.A, DA.B and DA.C. The second domain "Use of Architecture (UA)" has three control objectives: UA.A, UA.B and UA.C. The third domain "Alignment with Business (AB)" has also three control objectives: AB.A, AB.B, AB.C. Figure 3 illustrates the interdependencies between the control objectives of the two domains.

For example, according to the interdependencies Table 3, DA.C depends on DA.B which depends on DA.A. This means that this control objective cannot be achieved unless the two others control objectives are achieved. The symbol $X$ means a direct dependence. The symbol $(X)$ means a transitive dependence.

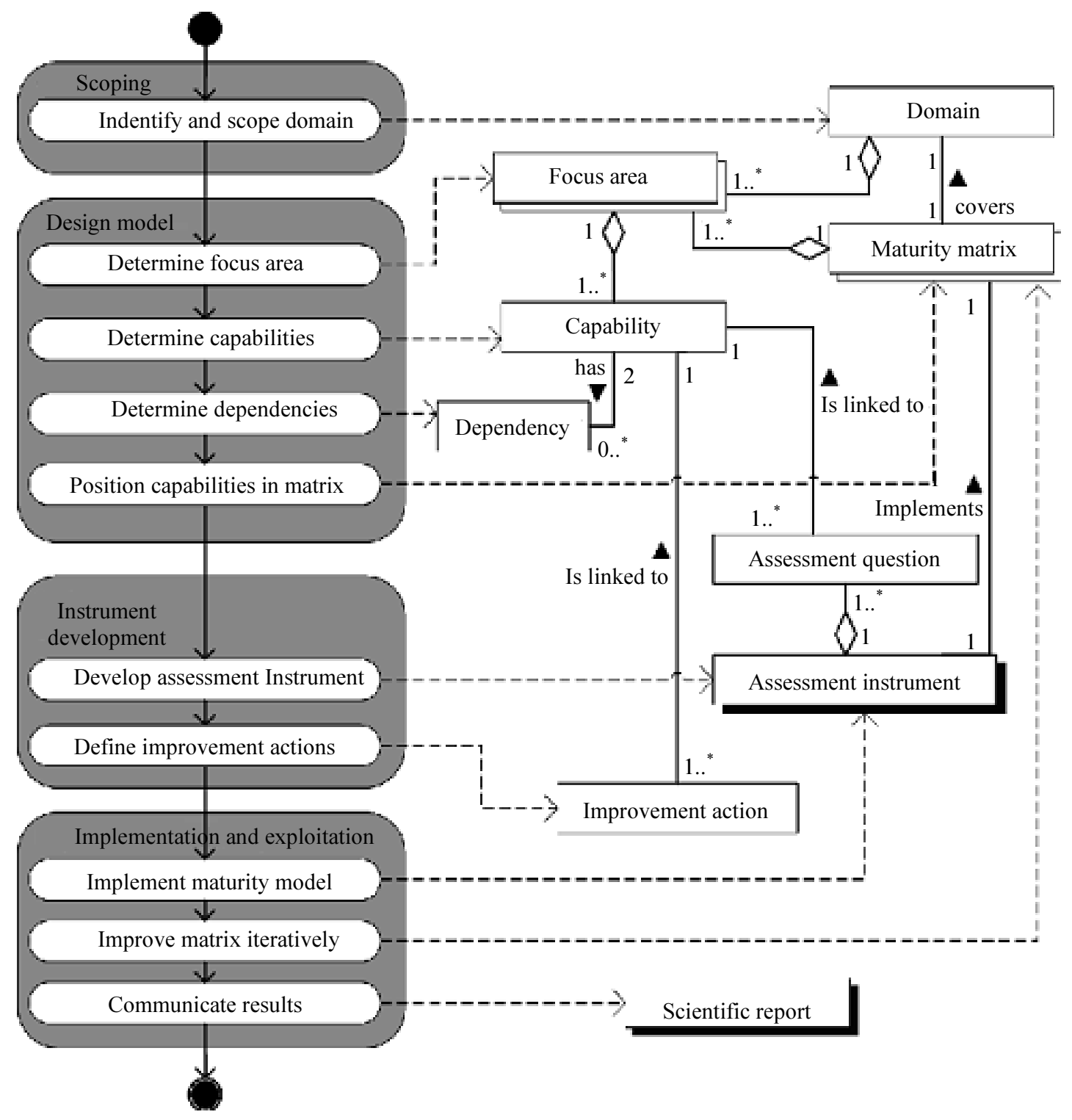

Fig. 2: The development method for focus area maturity models (Steenbergen et al., 2010) 


\begin{tabular}{|c|c|c|c|c|c|c|c|c|c|c|c|c|c|c|}
\hline Focus area $\quad$ Maturity scale & 0 & 1 & 2 & 3 & 4 & 5 & 6 & 7 & 8 & 9 & 10 & 11 & 12 & 13 \\
\hline Development of architecture & & A & & & $\mathrm{B}$ & & & $\mathrm{C}$ & & & & & & \\
\hline Use of architecture & & & A & & & $\mathrm{B}$ & & & & $\mathrm{C}$ & & & & \\
\hline Alignment with business & & A & & & & $\mathrm{B}$ & & & & $\mathrm{C}$ & & & & \\
\hline Alignment with development process & & & $\mathrm{A}$ & & & & $\mathrm{B}$ & & $\mathrm{C}$ & & & & & \\
\hline Alignment with operations & & & & & A & & & $\mathrm{B}$ & & & $\mathrm{C}$ & & & \\
\hline Relationship to the as-is state & & & & & A & & & & $\mathrm{B}$ & & & & & \\
\hline Roles and responsibilities & & & & A & & $\mathrm{B}$ & & & & & $\mathrm{C}$ & & & \\
\hline Coordination of developments & & & & & & & A & & & $\mathrm{B}$ & & & & \\
\hline Monitoring & & & & A & & $\mathrm{B}$ & & $\mathrm{C}$ & & $\mathrm{D}$ & & & & \\
\hline Quality management & & & & & & & & A & & $\mathrm{B}$ & & & $\mathrm{C}$ & \\
\hline Maintenance of the architectural process & & & & & & & A & & $\mathrm{B}$ & & $\mathrm{C}$ & & & \\
\hline Maintenance of the architectural deliverables & & & & & A & & & $\mathrm{B}$ & & & & & $\mathrm{C}$ & \\
\hline Commitment and motivation & & A & & & & & $\mathrm{B}$ & & $\mathrm{C}$ & & & & & \\
\hline Architectural roles and training & & & & A & & $\mathrm{B}$ & & & $\mathrm{C}$ & & & $\mathrm{D}$ & & \\
\hline Use of an architectural method & & & & A & & & & & & $\mathrm{B}$ & & & & $\mathrm{C}$ \\
\hline Consultation & & & A & & $\mathrm{B}$ & & & & $\mathrm{C}$ & & & & & \\
\hline Architectural tools & & & & & & & A & & & & $\mathrm{B}$ & & & $\mathrm{C}$ \\
\hline Budgeting and planning & & & & $\mathrm{A}$ & & & & & & & $\mathrm{B}$ & & $\mathrm{C}$ & \\
\hline
\end{tabular}

Fig. 3: Example of FA model maturity matrix

\section{Related Work}

Related work on the literature can be classified into three axes: (1) Generics risk management maturity models, (2) Generics project risk maturity models and (3) Information System (or one of its components like IT) risk management maturity models. The comparative analysis of maturity models aims to evaluate them based on a set of well-defined criteria. These are deduced from the problem as well as the background elements. These criteria are:

- Genericity: The proposed solution must be generic from the point of view of the IS risk management process and concept

- Independence of the context of application: The solution must be applicable in all the contexts and sectors of activity

- Adaptability: The solution must make it possible to take into account the specificities of the context where the model is applied

- Transparency: The solution must ensure the documentation and the traceability of the measures of maturity

- Improvement plan: Does the model assist its users in defining an improvement plan?

- Theoretical basis: Is the model based on the theoretical aspect of the domain studied for measuring maturity?

- Suitability for needs (IS RM): Is the model suitable for IS risk management and consider all aspects of an IS?

Table 5 presents the result of the evaluation of the maturity models according to the criteria mentioned above.
The results show that the model that best meets the evaluation criteria is the ISR3M model. The second observation is that none of the studied models presents an accompaniment to assist users in the development of the improvement plan resulting from the evaluation of the maturity.

Next section presents our proposed algorithm to define an improvement plan for the ISR3M model and all model based on FA architecture which is the best suitable model for risk management maturity model evaluation.

\section{Improvement Plan Definition Algorithm: "Path Prerequisites"}

The aim of the focus area maturity model is to describe a functional domain using a partition of adequate criteria which allows a more accurate assessment of the maturity. In particular, each criterion is given a score ranging over $A, B, C, \ldots$ depending on the maturity of the criterion. The set of (partial) scores gives an overall maturity score for the functional domain. Moreover, focus area criteria are defined using dependency (binary and transitive) relations stating for instance that some criterion cannot have the score $\mathrm{v}$ unless some other criteria have already reached some values (defined by the model). For example, we can have in a model that the focus area (or criterion) $X$ cannot reach the value $X . B$ unless some criteria $Y$ and $Z$ have respectively the values $Y . B$ and Z.C. Hence, in order to define a clear improvement plan to go from an Initial 
Configuration (IC) to a Target one (TC), we have to consider dependency relations and propose intermediate improvement leading (among others) to reach (if it is not already the case) the scores $Y . B$ and Z.C. Such a task can be tricky especially if the dependency relations are somewhat complex. To the best of our knowledge, no work has been done to tackle this aspect, i.e., no algorithm has been considered to propose, given a focus area maturity model and a set of dependencies, an improvement plan allowing to reach a target configuration TC from an initial configuration IC. In the following, we propose such an algorithm. First, we model the dependency rules using a directed acyclic graph where the set of vertices corresponds to the set of all possible scores for all focus areas. Hence if we consider for example a focus area $\mathrm{X}$ which can have three score values $\mathrm{A}, \mathrm{B}$ and $\mathrm{C}$, we shall then consider three vertices $X . A, X . B$ and X.C. The edges of the graph are based on direct dependencies. If a focus area $\mathrm{X}$ depends on a focus area $Y$ such that for $X$ to reach the value $v_{X}$ it is mandatory that $Y$ reaches the value $v_{Y}$ then in the graph we will have a directed edge $e=\left(X . v_{X}, Y . v_{Y}\right)$. The resulting graph describes the interdependencies between focus area values. Formally, we define the focus area interdependencies graph FAIG as:

FAIG $=(S, R)$ where $S$ is a set of vertices such that: $S=\cup S_{F} A$ and $S_{F A}=\cup\left\{\left\{\left[F A \rrbracket_{i}\right\}\right.\right.$ with each

$\llbracket F A \rrbracket_{i}$ stands for a different score value of FA.

$R$ is the set of arcs in the graph, $R=\left\{\left(X . v_{X}, Y \cdot v_{Y}\right)\right\}$ such that $X . v_{X}, Y . v_{Y} \in S$ and it is not possible to reach the score value vX for the focus area $X$ if the score value $v_{Y}$ of $Y$ is not yet reached.

Actually, a score value $v_{X}$ for a focus area $X$ can depend on more than one other focus area $Y$. We define $R^{*}$ the transitive closure of $R$ (seen as a binary relation).

We propose an algorithm to compute all possible paths from a target configuration (the set of all scores we want) to an initial configuration (the set of all current scores). We give an example (Fig. 5) based on the interdependencies matrix above (Fig. 4) to illustrate our aim: This graph specifies that $D A . B$ cannot be reached if $D A . A$ is not, that $U A . B$ cannot be reached if both $D A . B$ and $U A . A$ are not and so on.

If we consider that initially we have the set $\{D A . A, U A . B, A B . A\}$ and we want to reach the target configuration $\{D A . B, U A . C, A B . C\}$ then we have to reach respectively, DA.B,UA.B and $A B . B$. We will have actually the paths depicted on Fig. 6 .

In our setting, the dependencies are considered as conjunctive ones. For example, considering the dependency graph of Graph 1, $A B . C$ cannot be reached unless both $U A . B$ and $A B . B$ are reached. Improvement plans we need an exhaustive traversal of the graph going from the target vertices to current ones. Since the graph is acyclic, the algorithm always converges. The algorithm is straightforward, actually, we start from the target configuration (a set of target Control Objectives (COs) and we follow backwards direct connections in the graph to reach the initial configuration (the curret set of COs). As said before, since the graph is guarateed to be acyclic, our (backwards) graph traversal converges. Algorithm 1 provides a full description of the "Path Prerequisites" algorithm.

\begin{tabular}{|c|c|c|c|c|c|c|c|c|c|}
\hline Depends on & DA.A & DA.B & DA.C & UA.A & UA.B & UA.C & AB.A & AB.B & AB.C \\
\hline DA.A & & & & & & & & & \\
\hline DA.B & $\mathrm{X}$ & & & & & & & & \\
\hline DA.C & $(\mathrm{X})$ & $\mathrm{X}$ & & & & & & & \\
\hline UA.A & $\mathrm{X}$ & -- & -- & & & & & & \\
\hline UA.B & $(\mathrm{X})$ & $\mathrm{X}$ & -- & $\mathrm{X}$ & & & & & \\
\hline UA.C & $(\mathrm{X})$ & $(\mathrm{X})$ & $\mathrm{X}$ & $(\mathrm{X})$ & $\mathrm{X}$ & & & & \\
\hline AB.A & -- & -- & -- & -- & -- & -- & & & \\
\hline AB.B & $(\mathrm{X})$ & -- & -- & $\mathrm{X}$ & -- & -- & $\mathrm{X}$ & & \\
\hline AB.C & $(\mathrm{X})$ & $(\mathrm{X})$ & -- & $(\mathrm{X})$ & $\mathrm{X}$ & -- & $(\mathrm{X})$ & $\mathrm{X}$ & \\
\hline
\end{tabular}

Fig. 4: Example of interdependencies matrix 


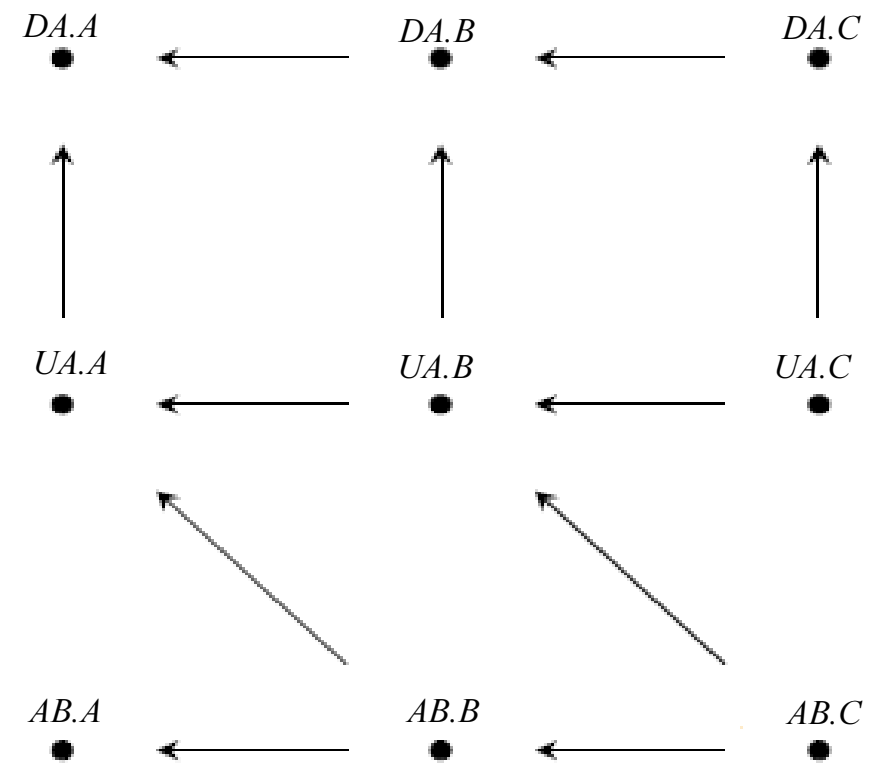

Fig. 5: FAIG example

$D A . C \rightarrow D A . B \rightarrow D A . A$
$U A . C \rightarrow U A . B \rightarrow D A . B \rightarrow D A . A$
$U A . C \rightarrow U A . B \rightarrow U A . A$
$A B . C \rightarrow A B . B \rightarrow A B . A$
$A B . C \rightarrow A B . B \rightarrow U A . A$
$A B . C \rightarrow U A . B \rightarrow D A . B \rightarrow$ DA.A
$A B . C \rightarrow U A . B \rightarrow U A . A$

Fig. 6: Resulting paths

Table 5: Comparative analysis of maturity models

\begin{tabular}{|c|c|c|c|c|c|c|c|c|}
\hline Model & Objective & Genericity & $\begin{array}{l}\text { Independence of the } \\
\text { context of application }\end{array}$ & Adaptability & Transparency & $\begin{array}{l}\text { Improvement } \\
\text { plan }\end{array}$ & $\begin{array}{l}\text { Theoretical } \\
\text { basis }\end{array}$ & $\begin{array}{l}\text { Suitability for } \\
\text { needs (IS RM) }\end{array}$ \\
\hline RMM & $\begin{array}{l}\text { Risk maturity Model } \\
\text { (Hillson, 1997) }\end{array}$ & - & + & - & - & - & - & -6 \\
\hline Project RMM & $\begin{array}{l}\text { Project Risk Maturity } \\
\text { Model (Hopkinson, 2011) }\end{array}$ & - & + & - & + & - & - & - \\
\hline COPS & $\begin{array}{l}\text { Risk Management Capability } \\
\text { Maturity Model for Complex } \\
\text { Product Systems Projects } \\
\text { (Ren and Yeo, 2004) }\end{array}$ & - & + & - & + & - & - & - \\
\hline $\begin{array}{l}\text { ERMM Level } \\
\text { Assessment Tool }\end{array}$ & $\begin{array}{l}\text { Enterprise Risk Management } \\
\text { Maturity-Level Assessment } \\
\text { Tool (Caralli and Knight, 2012a) }\end{array}$ & + & + & - & + & - & - & - \\
\hline $\begin{array}{l}\text { IT Risk } \\
\text { Management: A } \\
\text { Capability } \\
\text { Maturity } \\
\text { Model }\end{array}$ & $\begin{array}{l}\text { IT Risk Management } \\
\text { (Carcary, 2013) }\end{array}$ & - & + & - & + & - & & $+(\mathrm{IT})$ \\
\hline CMMI & $\begin{array}{l}\text { Guide for improving software } \\
\text { development and maintenance } \\
\text { practices. Guide for improving } \\
\text { software development and } \\
\text { maintenance practices } \\
\text { (Basque, 2011) }\end{array}$ & - & + & - & + & - & + & $\begin{array}{l}+(\text { Software } \\
\text { development })\end{array}$ \\
\hline MMGRSeg & $\begin{array}{l}\text { Measures the maturity level of } \\
\text { the information security related } \\
\text { to risk management process } \\
\text { (Mayer and Lemes Fagundes, 2009) }\end{array}$ & + & + & - & - & - & - & + (IT security) \\
\hline $\begin{array}{l}\text { IT Risk } \\
\text { maturity model }\end{array}$ & $\begin{array}{l}\text { Framework proposed by the } \\
\text { Information Systems Audit } \\
\text { and Control Association (ISACA) } \\
\text { for IT risk management (Isa, 2012) }\end{array}$ & - & + & - & + & - & + & + \\
\hline ISR3M & $\begin{array}{l}\text { Information System Risk } \\
\text { Management Maturity } \\
\text { Model (Elmaallam } \text { et al., 2019) }\end{array}$ & + & + & + & + & - & + & + \\
\hline
\end{tabular}




\section{Application of the "Path Prerequisites" Algorithm on ISR3M Maturity Model}

Information Systems Risk Management Maturity Model (ISR3M) (Elmaallam et al., 2019) aims to evaluate Information System (IS) risk management. An IS is defined as a special case of work system (Alter and Sherer, 2004). The elements to consider in the study of such systems are: participants, information, technology, processes, products and services, customers, infrastructure, environment and strategy. As for the risk management, we adopt the ISO 31000 Framework (ISO, 2009a) with the generic management cycle proposed by Sienou (2009). This cycle resumes the stages of the process proposed by ISO 31000 with a restructuring of its phases. Indeed: (1) Communication is considered as an activity inherent to every phase of the process (Sienou, 2009), (2) the cycle of management preserves its iterative character, but no longer requires synchronization of all stages with a monitoring phase (Sienou, 2009) and (3) Treatment may be the cause of a new iteration process (Sienou, 2009). The development of ISR3M model should provide answers to the problem of assessing IS risk management from two perspectives (Elmaallam and Kriouile, 2015). The first perspective is academic. The model must address a problem not sufficiently addressed in IS research: The assessment of IS risk management. The proposed solution must also be able to open new perspectives and opportunities in scientific research in this area. The second perspective relates to the practical side. The proposed model should be easy to implement and comply with the best practices of risk management. This model is developed using MMDPIS process (Elmaallam and Kriouile, 2014) and aims to satisfy seven principal requirements: (1) Genericity, (2) Independence of application context, (3) adaptability, (4) transparency, (5): plan improvement, (6) Theoretical basis and (7) Need adequacy (IS RM topic) (Elmaallam and Kriouile, 2015). It's structured along two dimensions. The first dimension includes evaluated activities. It is a matter of risk management activities.

\begin{tabular}{|c|c|c|c|c|c|c|c|c|c|c|c|c|c|c|}
\hline $\mathbf{N}^{\circ}$ & Area & $\mathbf{0}$ & 1 & 2 & 3 & 4 & 5 & 6 & 7 & 8 & 9 & 10 & 11 & 12 \\
\hline \multirow[t]{2}{*}{1} & RM Principles (PRM) & & $\mathrm{A}$ & $\mathrm{B}$ & $\mathrm{C}$ & & & & & & & & & \\
\hline & Organizational Framework & & & & & & & & & & & & & \\
\hline 2 & Mandate and commitment (ME) & & $\mathrm{A}$ & $\mathrm{B}$ & & & & & & & & & & \\
\hline 3 & Framework design (CCO) & & & $\mathrm{A}$ & B & $\mathrm{C}$ & $\mathrm{D}$ & $\mathrm{E}$ & & & & & & \\
\hline 4 & Risk management implementation (MOE) & & & & & $\mathrm{A}$ & & $\mathrm{B}$ & $\mathrm{C}$ & & & & & \\
\hline 5 & Monitoring and review (SRC) & & & & & & $\mathrm{A}$ & & & B & $\mathrm{C}$ & & & \\
\hline \multirow[t]{3}{*}{6} & Continual improvement (ACC) & & & & & & & $\mathrm{A}$ & & & B & $\mathrm{C}$ & & \\
\hline & Process & & & & & & & & & & & & & \\
\hline & Establishment of context & & & & & & & & & & & & & \\
\hline 7 & External context (ECX) & & $\mathrm{A}$ & $\mathrm{B}$ & $\mathrm{C}$ & & & & & & & & & \\
\hline 8 & Internal context (ECP) & & $\mathrm{A}$ & $\mathrm{B}$ & $\mathrm{C}$ & & & & & & & & & \\
\hline 9 & Process context (ECP) & & A & & B & $\mathrm{C}$ & $\mathrm{D}$ & & & & & & & \\
\hline \multirow[t]{2}{*}{10} & Risk management criteria (ECC) & & & $\mathrm{A}$ & & & $\mathrm{B}$ & $\mathrm{C}$ & & & & & & \\
\hline & Risk assessment & & & & & & & & & & & & & \\
\hline 11 & Risk identification (API) & & & & A & & $\mathrm{B}$ & $\mathrm{C}$ & $\mathrm{D}$ & $\mathrm{E}$ & & & & \\
\hline 12 & Risk analysis (APA) & & & & & $\mathrm{A}$ & & $\mathrm{B}$ & $\mathrm{C}$ & & & & & \\
\hline \multirow[t]{2}{*}{13} & Risk evaluation (APV) & & & & & $\mathrm{A}$ & & & B & $\mathrm{C}$ & & & & \\
\hline & Treatment & & & & & & & & & & & & & \\
\hline 14 & Selection of treatment option (TSO) & & & & & $\mathrm{A}$ & & & & B & $\mathrm{C}$ & & & \\
\hline 15 & Elaboration of treatment plan (TEP) & & & & & $\mathrm{A}$ & & & & & B & $\mathrm{C}$ & & \\
\hline 16 & Implementing of treatment plan (TMP) & & & & & & $\mathrm{A}$ & & & & & B & $\mathrm{C}$ & \\
\hline 17 & Process monitoring and review (SR) & & & & & & & $\mathrm{A}$ & & & & & $\mathrm{B}$ & $\mathrm{C}$ \\
\hline 18 & Recording (Eng) & & $\mathrm{A}$ & $\mathrm{B}$ & $\mathrm{C}$ & & & & & & & & & \\
\hline
\end{tabular}

Fig. 7: ISR3M positioning maturity matrix (Elmaallam et al., 2019) 


\begin{tabular}{|c|c|c|c|c|c|c|c|c|c|c|c|c|c|c|}
\hline $\mathrm{N}^{\circ}$ & Area & 0 & 1 & 2 & 3 & 4 & 5 & 6 & 78 & 8 & 9 & 10 & 11 & 12 \\
\hline 1 & RM principles (PRM) & & $\mathrm{A}$ & $\mathrm{B}$ & $\mathrm{C}$ & & & & & & & & & \\
\hline 2 & Mandate and commitment (ME) & & A & B & & & & & & & & & & \\
\hline 3 & Design of framework (CCO) & & & $\mathrm{A}$ & $\mathrm{B}$ & $\mathrm{C}$ & $\mathrm{D}$ & E & & & & & & \\
\hline 4 & Risk management implementation (MOE) & & & & & A & & B & $\mathrm{C}$ & & & & & \\
\hline 5 & Monitoring and review (SRC) & & & & & & A & & & $\mathrm{B}$ & $\mathrm{C}$ & & & \\
\hline 6 & Continual improvement (ACC) & & & & & & & A & & & B & $\mathrm{C}$ & & \\
\hline 7 & External context (ECX) & & $\mathrm{A}$ & B & $\mathrm{C}$ & & & & & & & & & \\
\hline 8 & Internal context (ECP) & & $\mathrm{A}$ & $\mathrm{B}$ & $\mathrm{C}$ & & & & & & & & & \\
\hline 9 & Process context (ECP) & & A & & $\mathrm{B}$ & $\mathrm{C}$ & $\mathrm{D}$ & & & & & & & \\
\hline 10 & Risk management criteria (ECC) & & & $\mathrm{A}$ & & & B & $\mathrm{C}$ & & & & & & \\
\hline 11 & Risk identification (API) & & & & $\mathrm{A}$ & & B & $\mathrm{C}$ & $\mathrm{D} 1$ & $\mathrm{E}$ & & & & \\
\hline 12 & Risk analysis (APA) & & & & & $\mathrm{A}$ & & B & $\mathrm{C}$ & & & & & \\
\hline 13 & Risk evaluation (APV) & & & & & $\mathrm{A}$ & & & $\mathrm{B}$ & C & & & & \\
\hline 14 & Selection of treatment option (TSO) & & & & & $\mathrm{A}$ & & & & B & $\mathrm{C}$ & & & \\
\hline 15 & Elaboration of treatment plan (TEP) & & & & & $\mathrm{A}$ & & & & & B & $\mathrm{C}$ & & \\
\hline 16 & Implementing of treatment plan (TMP) & & & & & & A & & & & & B & $\mathrm{C}$ & \\
\hline 17 & Monitoring and review (SR) & & & & & & & A & & & & & $\mathrm{B}$ & C \\
\hline 18 & Recording (Eng) & & A & $\mathrm{B}$ & $\mathrm{C}$ & & & & & & & & & \\
\hline
\end{tabular}

Fig. 8: Example of maturity matrix for initial configuration

\begin{tabular}{|c|c|c|c|c|c|c|c|c|c|c|c|c|c|c|}
\hline $\mathrm{N}^{\circ}$ & Area & 0 & 1 & 2 & 3 & 4 & 5 & 6 & 7 & 8 & 9 & 10 & 11 & 12 \\
\hline 1 & RM principles (PRM) & & A & B & $\mathrm{C}$ & & & & & & & & & \\
\hline 2 & Mandate and commitment (ME) & & A & B & & & & & & & & & & \\
\hline 3 & Design of framework (CCO) & & & $\mathrm{A}$ & B & $\mathrm{C}$ & $\mathrm{D}$ & $\mathrm{E}$ & & & & & & \\
\hline 4 & Risk management implementation (MOE) & & & & & $\mathrm{A}$ & & $\mathrm{B}$ & $\mathrm{C}$ & & & & & \\
\hline 5 & Monitoring and review (SRC) & & & & & & A & & & B & $\mathrm{C}$ & & & \\
\hline 6 & Continual improvement (ACC) & & & & & & & $\mathrm{A}$ & & & $\mathrm{B}$ & $\mathrm{C}$ & & \\
\hline 7 & External context (ECX) & & A & B & $\mathrm{C}$ & & & & & & & & & \\
\hline 8 & Internal context $(\mathrm{ECP})$ & & A & $\mathrm{B}$ & $\mathrm{C}$ & & & & & & & & & \\
\hline 9 & Process context (ECP) & & A & & $\mathrm{B}$ & $\mathrm{C}$ & $\mathrm{D}$ & & & & & & & \\
\hline 10 & Risk management criteria (ECC) & & & A & & & B & $\mathrm{C}$ & & & & & & \\
\hline 11 & Risk identification (API) & & & & $\mathrm{A}$ & & B & $\mathrm{C}$ & $\mathrm{D}$ & E & & & & \\
\hline 12 & Risk analysis (APA) & & & & & A & & B & $\mathrm{C}$ & & & & & \\
\hline 13 & Risk evaluation (APV) & & & & & A & & & $\mathrm{B}$ & $\mathrm{C}$ & & & & \\
\hline 14 & Selection of treatment option (TSO) & & & & & A & & & & $\mathrm{B}$ & $\mathrm{C}$ & & & \\
\hline 15 & Elaboration of treatment plan (TEP) & & & & & A & & & & & B & $\mathrm{C}$ & & \\
\hline 16 & Implementing of treatment plan (TMP) & & & & & & A & & & & & $\mathrm{B}$ & $\mathrm{C}$ & \\
\hline 17 & Monitoring and review (SR) & & & & & & & $\mathrm{A}$ & & & & & $\mathrm{B}$ & $\mathrm{C}$ \\
\hline 18 & Recording (Eng) & & A & $\mathrm{B}$ & $\mathrm{C}$ & & & & & & & & & \\
\hline
\end{tabular}

Fig. 9: Example of maturity matrix for target configuration 
The projected improvements are illustrated in Table 6. Areas which are not subject of improvement are not mentioned

\section{Results}

In this section, we present the exhaustive result of applying "Path Prerequisites" algorithm on ISR3M maturity model.

Table 7 provides all required $\mathrm{CO}$ to achieve the target set given in Table 6 .

According to the results above, the treatment plan should contain the actions required to achieve the control objectives of each area. For example, to achieve the APA.B, the organization must:

Table 6: Target control objectives by area

\begin{tabular}{lll}
\hline & CO initial Set & CO Target set \\
\hline PRM & A & B \\
ME & A & B \\
CCO & A & B \\
MOE & -- & B \\
SRC & -- & B \\
ACC & -- & A \\
ECI & B & C \\
ECP & A & D \\
ECC & -- & C \\
API & A & E \\
APA & A & C \\
APV & A & C \\
TSO & A & C \\
TEP & A & C \\
TMP & A & C \\
SR & -- & C \\
Eng & -- & C \\
\hline
\end{tabular}

- Use tools and techniques for risks analysis of all IS component

- Ensure obtaining results of analysis allowing estimating the risks

- Define the strategies and the methods of treatment during the analysis

- Consider and communicate to the stakeholders the degrees of confidence in the determination of the level of the risk and its sensibility in prerequisites and in hypotheses

- Mention and underline factors such as: the difference of opinion between experts (IT, process), the uncertainty, the availability, the quality, the quantity and the validity of the relevance of the data/ information or the limits of modellings

Table 7: Control objective to achieve

\begin{tabular}{ll}
\hline Area & Control objective \\
\hline RM principles (PRM) & PRM.B \\
Mandate and commitment (ME) & ME.B \\
Framework design (CCO) & CCO.B, CCO.C \\
Risk management implementation (MOE) & MOE.A, MOE.B \\
Monitoring and review (SRC) & SRC.A, SRC.B \\
Continual improvement (ACC) & ACC.A \\
External context (ECX) & -- \\
Internal context (ECI) & ECI.C \\
Process context (ECP) & ECP.B, ECP.C, ECP.D \\
Risk Management criteria (ECC) & ECC.A, ECC.B; ECC.C \\
Risk Identification (API) & API.B, API.C, API.D, API.E \\
Risk Analysis (APA) & APA.B, APA.C \\
Risk Evaluation (APV) & APV.B, APV.C \\
Selection of treatment Option (TSO) & TSO.B, TSO.C \\
Elaboration of treatment plan (TEP) & TEP.B, TEP.C \\
Implementing treatment plan (TMP) & TMP.B, TMP.C \\
Monitoring and review (SR) & SR.A; SR.B, SR.C \\
Recording (Eng) & Eng.A, Eng.B, Eng.C \\
\hline
\end{tabular}

Table 8: "Path Prerequisites" results for RM principles

\begin{tabular}{llll}
\hline Area & Init. CO & Targ. CO & Ways \\
\hline PMR & A & B & pmr.b->pmr.a-> \\
\hline
\end{tabular}

Table 9: "Path Prerequisites" results for organizational framework

\begin{tabular}{|c|c|c|c|}
\hline Area & Init. CO & Targ. CO & Ways \\
\hline ME & A & B & me.b->me.a-> \\
\hline $\mathrm{CCO}$ & A & B & $\begin{array}{l}\text { cco.b->me.a- }> \\
\text { cco.b->me.b->me.a-> }\end{array}$ \\
\hline MOE & -- & B & $\begin{array}{l}\text { moe. } b->\text { moe. } a->\text { cco.a- }> \\
\text { moe. } b->\text { cco.c->cco.b->me.a } \\
\text { moe.b->cco.c->cco.b->me.b->me.a-> }\end{array}$ \\
\hline ECC & -- & $\mathrm{C}$ & $\begin{array}{l}\text { src.b->src.a->moe. } a->\text { cco.a-> } \\
\text { src.b->moe.b->moe.a->cco.a } \\
\text { src.b->moe.b->cco.c->cco.b->me.a-> } \\
\text { src.b->moe.b->cco.c->cco.b->me.b->me.a-> }\end{array}$ \\
\hline ACC & -- & A & acc.a->src.a->moe.a->cco.a-> \\
\hline
\end{tabular}

Table 10: "Path Prerequisites" results for context establishment activity of RM process

\begin{tabular}{llll}
\hline Area & Init. CO & Targ. CO & Ways \\
\hline ECX & C & C & -- \\
ECI & B & C & eci.c->eci.b-> \\
ECP & A & D & ecp.d->ecp.c->ecp.b-> \\
ECC & -- & C & ecc.c->ecc.b->ecp.b->ecc.a-> \\
& & & ecc.c->ecp.c->ecp.b-> \\
\hline
\end{tabular}


Table 11: "Path Prerequisites" results for appreciation activity of RM process

\begin{tabular}{|c|c|c|c|}
\hline Area & Init. CO & Targ. CO & Ways \\
\hline$\overline{\mathrm{API}}$ & A & $\mathrm{E}$ & $\begin{array}{l}\text { api.e->api.d->api.c->api.b->api.a-> } \\
\text { api.e->api.d->api.c->api.b->ecp.c->ecp.b }\end{array}$ \\
\hline APA & A & $\mathrm{C}$ & $\begin{array}{l}\text { apa.c->apa.b->apa.a-> } \\
\text { apa.c->apa.b->ecp.c->ecp.b-> } \\
\text { apa.c->api.b->api.a-> } \\
\text { apa.c->api.b->ecp.c->ecp.b-> }\end{array}$ \\
\hline APV & A & $\mathrm{C}$ & $\begin{array}{l}\text { apv.c->apv.b->apv.a-> } \\
\text { apv.c->apv.b->apa.b->apa.a-> } \\
\text { apv.c->apv.b->apa.b->ecp.c->ecp.b-> } \\
\text { apv.c->apa.c->apa.b->apa.a-> } \\
\text { apv.c->apa.c->apa.b->ecp.c->ecp.b-> } \\
\text { apv.c->apa.c->api.b->api.a-> } \\
\text { apv.c->apa.c->api.b->ecp.c->ecp.b-> }\end{array}$ \\
\hline
\end{tabular}

Table 12: "Path Prerequisites" results for monitoring and review activity of RM process

\begin{tabular}{llll}
\hline Area & Init. CO & Targ. CO & Ways \\
\hline SR & -- & C & sr.c->sr.b->sr.a- $>$ tmp.a-> \\
\hline
\end{tabular}

Table 13: "Path Prerequisites" results for monitoring and review activity of RM process

\begin{tabular}{llll}
\hline Area & Init. CO & Targ. CO & Ways \\
\hline Eng & -- & C & eng.c->eng.b->eng.a-> \\
\hline
\end{tabular}

Table 14: "Path Prerequisites" results for treatment activity of RM process

\begin{tabular}{|c|c|c|c|}
\hline Area & Init. $\mathrm{CO}$ & Targ. CO & Ways \\
\hline $\mathrm{TSO}$ & $\mathrm{A}$ & $\mathrm{C}$ & $\begin{array}{l}\text { tso.c->tso.b->tso.a-> } \\
\text { tso.c->tso.b->apv.b->apv.a-> } \\
\text { tso.c->tso.b->apv.b->apa.b->apa.a-> } \\
\text { tso.c->tso.b->apv.b->apa.b->ecp.c->ecp.b-> } \\
\text { tso.c->apv.c->apv.b->apv.a-> } \\
\text { tso.c->apv.c->apv.b->apa.b->apa.a-> } \\
\text { tso.c->apv.c->apv.b->apa.b->ecp.c->ecp.b-> } \\
\text { tso.c->apv.c->apa.c->apa.b->apa.a-> } \\
\text { tso.c->apv.c->apa.c->apa.b->ecp.c->ecp.b-> } \\
\text { tso.c->apv.c->apa.c->api.b->api.a-> } \\
\text { tso.c->apv.c->apa.c->api.b->ecp.c->ecp.b-> }\end{array}$ \\
\hline TEP & A & C & $\begin{array}{l}\text { tep.c->tep.b->tep.a-> } \\
\text { tep.c->tep.b->tso.b->tso.a-> } \\
\text { tep.c->tep.b->tso.b->apv.b->apv.a-> } \\
\text { tep.c->tep.b->tso.b->apv.b->apa.b->apa.a-> } \\
\text { tep.c->tep.b->tso.b->apv.b->apa.b->ecp.c->ecp.b-> } \\
\text { tep.c->tso.c->tso.b->tso.a-> } \\
\text { tep.c->tso.c->tso.b->apv.b->apv.a-> } \\
\text { tep.c->tso.c->tso.b->apv.b->apa.b->apa.a-> } \\
\text { tep.c->tso.c->tso.b->apv.b->apa.b->ecp.c->ecp.b-> } \\
\text { tep.c->tso.c->apv.c->apv.b->apv.a-> } \\
\text { tep.c->tso.c->apv.c->apv.b->apa.b->apa.a-> } \\
\text { tep.c->tso.c->apv.c->apv.b->apa.b->ecp.c->ecp.b-> } \\
\text { tep.c->tso.c->apv.c->apa.c->apa.b->apa.a-> } \\
\text { tep.c->tso.c->apv.c->apa.c->apa.b->ecp.c->ecp.b-> } \\
\text { tep.c->tso.c->apv.c->apa.c->api.b->api.a-> } \\
\text { tep.c->tso.c->apv.c->apa.c->api.b->ecp.c->ecp.b-> }\end{array}$ \\
\hline TMP & A & C & $\begin{array}{l}\text { tmp.c->tmp.b->tmp.a-> } \\
\text { tmp.c->tmp.b->tep.b->tep.a-> } \\
\text { tmp.c->tmp.b->tep.b->tso.b->tso.a-> } \\
\text { tmp.c->tmp.b->tep.b->tso.b->apv.b->apv.a-> } \\
\text { tmp.c->tmp.b->tep.b->tso.b->apv.b->apa.b->apa.a-> } \\
\text { tmp.c->tmp.b->tep.b->tso.b->apv.b->apa.b->ecp.c->ecp.b-> }\end{array}$ \\
\hline
\end{tabular}

Table 8-14 provide for each area the initial $\mathrm{CO}$ (Init. CO), the target $\mathrm{CO}$ (Targ. $\mathrm{CO}$ ) and the ways to follow to reach this last. These ways are the program (implementation of the "Path Prerequisites" algorithm) output.
The algorithm gives all paths leading to the current state to the target state and all control objectives to be achieved to reach the target state which is very difficult for maturity model's users to realize, especially when the activity interdependencies matrix is complex. 


\section{Conclusion}

In this study we propose an algorithm called "Path Prerequisites" to define the IS risk management improvement plan. Based on the FA architecture, which is the most suitable maturity architecture for IS risk management maturity assessment, this algorithm looks for all the paths to reach a target state of Control Objectives (CO) based on a $\mathrm{CO}$ current state and then devise the list of those which must be achieved. After presenting the FA maturity model and its specificities, we give the description and "pseudo code" of the proposed algorithm. We then applied it to the information system risk management field. The proposed approach is very useful for determining the improvement plan for activities characterized by the interdependency between their elements.

The definition of an improvement plan is made for a single information system. This assumes that the improvement strategy is rather bottom-up. The improvement is done for each information system of the company then occurs the consolidation to have a global maturity. One possible perspective of this work is to focus on the top-down improvement strategy: defining the plan for improving information systems risk management maturity from a global maturity target.

\section{Acknowledgement}

The authors would like to thank their respective team members for offering helpful conditions to work.

\section{Author's Contributions}

Soumaya Amraoui: Writed the core of the manuscript.

Dr. Mina El Maallam: Coordinated the work and helped with writing issues.

Dr. Hicham Bensaid: Contributed in algorithm design, in programming stuff and helped with latex issues.

\section{Ethics}

This article is original and contains unpublished material. The corresponding author confirms that all of the other authors have read and approved the manuscript and no ethical issues involved.

\section{References}

Alter, S.L. and S.A. Sherer, 2004. A general, but readily adaptable model of information system risk. Commun. Assoc. Inform. Syst., 14: 1-6.

Caralli, R. and M. Knight, 2012. Maturity models 101: A primer for applying maturity models to smart grid security, resilience and interoperability. Carnegie Mellon University, Software Engineering Institute.
Carlsson, S.A., S. Henningsson, S. Hrastinski and C. Keller, 2011. Socio-technical is design science research: developing design theory for is integration management. Inform. Syst. e-Bus. Manage., 9: 109-131.

Carvalho, J.V., A.L. Rocha, R. van de Wetering and A. Abreu, 2019. A maturity model for hospital information systems. J. Bus. Res., 94: 388-399.

Elmaallam, M. and A. Kriouile, 2013. Toward a Maturity Model Development Process for Information Systems (MMDEPSI). Int. J. Comput. Sci. Issues, 10: 118-125.

Elmaallam, M. and A. Kriouile, 2014. A generic process for the development and the implementation of is maturity models. Int. J. Comput. Sci. Issues, 11: 34-42.

Elmaallam, M. and A. Kriouile, 2015. Development of the ISR3M model for is risk management evaluation using the focus area structure according to the MMDPIS generic process. Transact. Machine Learn. Artificial Intel., 2: 106-106.

Elmaallam, M., H. Bensaid and A. Kriouile, 2019. A maturity model for assessing IS risk management activity considering the dependencies between its elements. Comput. Inform. Sci., 12: 98-111.

Herbsleb, J.D. and D.R. Goldenson, 1996. A systematic survey of CMM experience and results. Proceedings of the IEEE 18th International Conference on Software Engineering, Mar. 25-29, IEEE Xplore Press, Berlin, Germany, pp: 323-330. DOI: 10.1109/ICSE.1996.493427

Hevner, A.R., S.T. March, J. Park and S. Ram, 2004. Design science in information systems research. MIS Quarterly, 28: 75-105.

ISO, 2009a. ISO 31000:2009 risk management. Principles Guidelines Implementation.

ISO, 2009b. ISO guide 73:2009-risk managementvocabulary.

Iversen, J., P.A. Nielsen and J. Norbjerg, 1999. Situated assessment of problems in software development. ACM SIGMIS Database Adv. Inform. Syst., 30: 6681. DOI: $10.1145 / 383371.383376$

Koomen, T. and R. Baarda, 2006. TMap test topics. UTN Publishers.

Mayer, J. and L.L. Fagundes, 2009. A model to assess the maturity level of the risk management process in information security. Proceedings of the IFIP/IEEE International Symposium on Integrated Network Management-Workshops, (NMW'09), pp: 61-70.

Mettler, T., 2010. Thinking in terms of design decisions when developing maturity models. Int. J. Strategic Dec. Sci., 1: 77-88.

Olzak, T., 2008. A practical approach to managing information system risk.

Peffers, K., T. Tuunanen, M. Rothenberger and S. Chatterjee, 2007. A design science research methodology for information systems research. J. Manage. Inform. Syst., 24: 45-77. 
Proenca, D. and J. Borbinha, 2016. Maturity models for information systems-a state of the art. Procedia Comput. Sci., 100: 1042-1049. DOI: $10.1016 /$ j.procs.2016.09.279

Röglinger, M., J. Pöppelbuß and J. Becker, 2012. Maturity models in business process management. Bus. Process Manage. J., 18: 328-346.

Radut, C., 2009. The enterprise information system and risk management. Ann. Faculty Econ., 4: 1030-1034.

Rocha, A., 2011. Evolution of information systems and technologies maturity in healthcare. Int. J. Health Care Inform. Syst. Inform., 6: 28-36.

Rosemann, M. and T. de Bruin, 2005. Towards a business process management maturity model. Proceedings of the 13th European Conference on Information Systems, May 26-28, QUT, Germany, Regensburg.

Salvati, D., 2008. Management of information system risks.

Sienou, A., 2009. Proposition d'un cadre m'ethodologique pour le management int'egr'e des risques et des processus d'entreprise - a proposal of a methodological framework for the integrated management of risks and business processes. $\mathrm{PhD}$ Thesis.
Steenbergen, M.V., R. Bos, S. Brinkkemper, I.V. Weerd and W. Bekkers, 2010. The Design of Focus Area Maturity Models. In: Global Perspectives on Design Science Research, Winter, R., J.L. Zhao, (Eds.), Springer, Berlin, Heidelberg.

Stoneburner, G., A. Goguen and A. Feringa, 2002. Risk management guide for information technology systems. Nist Special Public., 800: 800-830.

Valentin, D. and F. Vasile, 2008. Erp implantation: Key factors of success and impact on performance. Ann. Faculty Econ., 4: 1353-1357.

Van Steenbergen, M., M. Van den Berg and S. Brinkkemper, 2007. A balanced approach to developing the enterprise architecture practice. Enterprise Inform. Syst., 12: 240-253.

Wade, M. and J. Hulland, 2004. Review: The resource based view and information systems research: Review, extension and suggestions for future research. MIS Q., 28: 107-142.

Weerd, I.V. and S. Brinkkemper, 2008. Meta-modeling for situational analysis and design methods.

Woodall, P., M. Oberhofer and A. Borek, 2014. A classification of data quality assessment and improvement methods. Int. J. Inform. Quality, 3: 298-298.

\section{Algorithm 1}

\section{"Path Prerequisites" Algorithm}

Purpose: The "Path Prerequisites" algorithm looks for all the paths to reach a COs target state based on a current Cos state, and then deduce the list of control objectives to achieve. The dependency constraints between the control objectives define a partial relation of order between them. They can be represented by directed graphs without loops, such as vertices and edges represent respectively the control objectives and the relation between them. One edge directed by an objective of control COi to another objective of control COj means that COi depends directly on COj. We consider the problem to provide from a current state of the control objectives, all prerequisites paths to reach a target state, while respecting the dependency constraints:

Input: CurrentStatus: the set containing the control objectives describing the current state,

TargetState: the set containing the CO target state.

Output: Paths: All paths leading to the current state to the target state,

List_CO_to_Achieve: all control objectives to be achieved to reach the target state.

Local variables: $P$ : stack of paths to be explored,

Path: current path.

\section{Algorithm:}

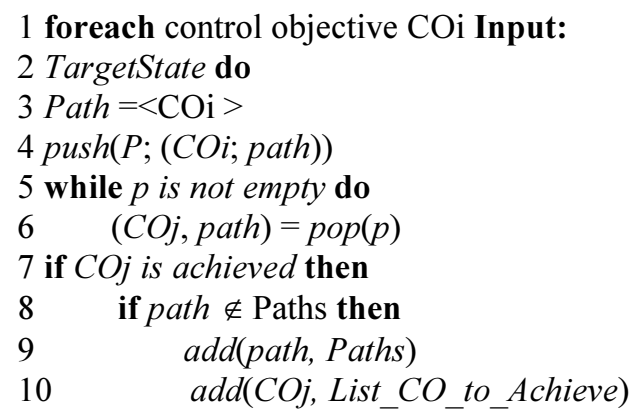




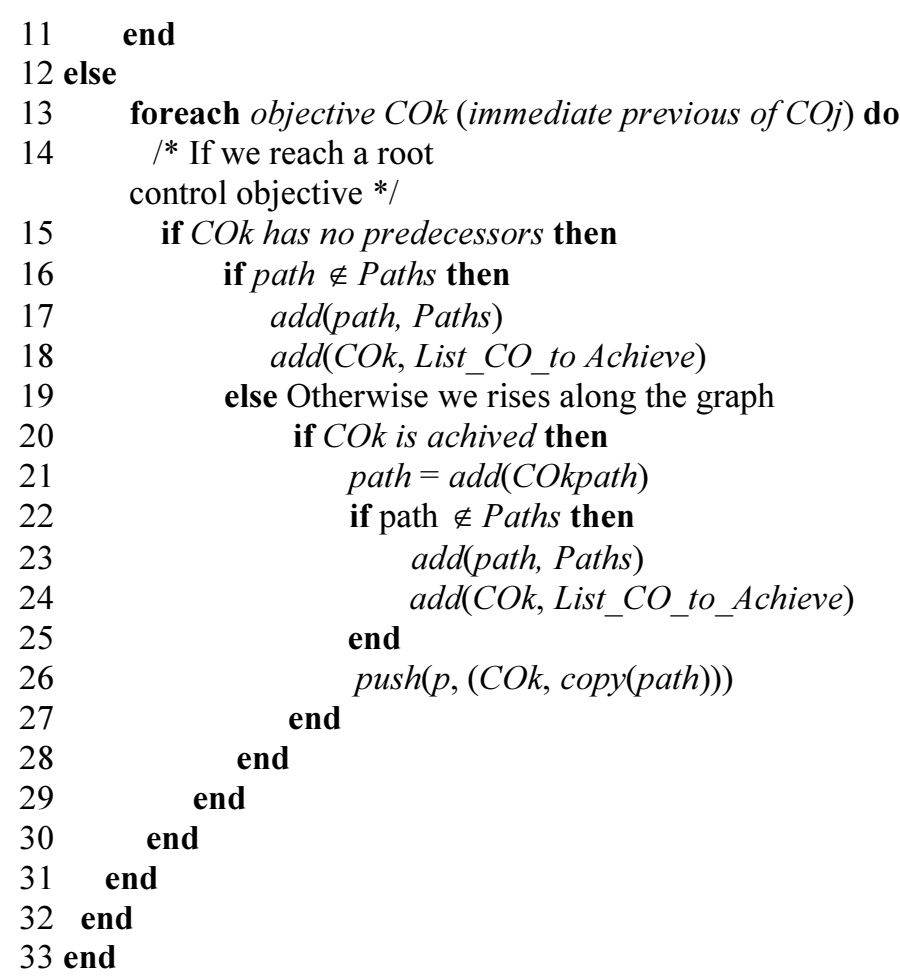

